\title{
How Gamification Can Help Family Businesses
}

\author{
Salvatore Tomaselli (Università degli Studi de Palermo) \\ Danilo Maurici
}

KEYWORDS: Leadership, Family Business, human resources.

Over the past several years games have been used in settings far beyond the video tournament, chess-playing session or poker marathon. "Gamification," using the dynamics and typical game-design elements in nongame contexts (Deterding, Dixon, Khaled, Nacke. 2011), is helping people learn new concepts, communicate better and connect with one another. The benefits of gamification have been spread to areas such as education, parenting, sustainability, healthcare and scientific research. Businesses have used games to train employees and to engage customers more deeply.

Our research has discovered that gamification can dramatically improve the success of family businesses as well. It can make it easier for these families to discuss serious topics such as the relationship between the family and the business and its impact on both systems, and to design policies, governance or strategy.

Sometimes it is challenging to engage family members in an intense and productive discussion, especially those who feel uninvolved in daily business activities or who are unfamiliar with some business concepts. They may feel the meetings are too formal and burdensome and avoid participating in the discussions. And even family members who are more involved in the business may feel uncomfortable discussing critical issues about the family or the relationship between the family and the business. Gamification can help.

In this article, we will first give a short introduction to gamification's primary aims and its essential elements and features. Then, we will offer some insights on some possible use of gamification in the context of business families and the benefits that it can provide.

\section{Gamification: A Description}

Gamification has been increasingly adopted in various business settings, such as marketing, recruiting,

training, business model generation, innovation, strategic planning and consulting,

The use of gamification is strongly driven by both utilitarian and hedonic (pleasure-seeking) benefits/motivations (Hamari, Koivisto. 2015). It creates an atmosphere of good cheer that keeps the mood light and fun, provides a break from the "burdensome" workgroup, and creates a context that facilitates empathy, communication and teamwork.

Furthermore, its ability to promote engagement and problem solving, frequently coupled with the use of visual tools that favor creative thinking, has made gamification a powerful tool that triggers lateral thinking and improves the ability of participants to organize their thoughts.

In this way, gamification allows participants to explore ideas, concepts, and contexts and serves to facilitate interaction, communication and collective learning, even among people with very different backgrounds and perspectives.

\section{Psychological Rewards and Measurable Results}

Gamification has been defined as "the craft of deriving fun and engaging elements found typically in games and thoughtfully applying them to real-world or productive activities" (Chou. 2015, p. 8). It has been largely used by companies in marketing and customer loyalty programs. More recently, companies have used it in training programs to motivate and engage employees and to stimulate innovation and enhance teamwork (Isdale, 2016).

Chou (2015, p. 10-11) reports that:

"The U.S. Armed Forces now spends more money on recruitment games than any other marketing platform.
Copyright ( 2019 The Authors. Entrepreneur \& Innovation Exchange is published at EIX.org. This is an open access article under the terms of the Creative Commons Attribution-NoDerivs License, which permits use and distribution in any medium, provided the original work is properly cited and no modifications or adaptations are made. View EIX.org Authorship Terms at https://eix.org/terms
FamilyBusiness 
Volkswagen generated 33 million web visits and 119,000 new ideas through its People's Car Project to design the 'perfect car.' Nike used gamified feedback to drive over 5,000,000 users to beat their personal fitness goals every day of the year. With Beat the GMAT, students increased the time they spent on the website, improving their test scores by $370 \%$ through a gamified platform. In 10 days, Foldit gamers solved an AIDS virus protein problem that had confounded researchers for 15-years."

Callois (1985) distinguishes among different types of games: "agon" games, based on competition or conflict, as in match- and racing games; "alea" games, nested in chance or luck (e.g. Wheel of Fortune); "mimicry," involving simulation and make-believe, for instance by assuming a role in children's play; and "ilinx," founded on dizziness, as in roller coasters; based on their structural complexity, there are "paidea" games, that are freely (i.e. less) organized, and "ludus" games, that highly organized.

Gamification uses game elements to engage and entertain participants while it changes their behavior and impacts their performance. It can improve learning, motivate and enhance participation in a given activity, strengthen collaboration and engagement, and help people solve a problem or reach a certain goal more quickly.

How does this happen? One explanation is that "Games have no other purpose than to please the humans playing them" (Chou. 2015 p. 9). Games offer people a healthy, fun, immersive and challenging activity that provides an engaging experience; and make them act differently than they would do in the "real world."

Research investigating chemical and neurological effects shows that when playing games, people experience a form of positive stress called "eustress" (Pinheiro et al. 2015). From a physiological point of view, eustress is a positive response to a stressor - or a situation that arouses an emotion, good or bad - where the effort of adaptation creates a sense of personal fulfillment, well-being and satisfaction of needs, the opposite of what happens in the case of distress, or negative stress, (Pinheiro et al. 2015). Lumsden, Edwards, Lawrence, Coyle \& Munafò (2016) report that the psychological conditions of a subject involved in a recreational activity transform the tension into an optimistic drive, freeing dopamine during crucial moments in the game.

In a 10-year study on the motivations and drivers that guide people in gamified contexts, Chou (2015) discovered that successful games appeal to certain "core drives" that guide the game participants towards a variety of activities and decisions. Some of these drivers stimulate the right brain, focusing on intrinsic motivations or tendencies like creativity, self-expression and social dynamics; others stimulate the left brain, focusing on extrinsic motivations or tendencies like logic, analytical thought and ownership. This research classified the core drives associated with gamified activities into eight groups: four right brain-related drives and four left brain-related drives. The four right brainrelated drives are Empowerment of Creativity \& Feedback; Epic Meaning \& Calling; Social Influence \& Relatedness; Unpredictability \& Curiosity. The four left brain-related drives that stimulate extrinsic tendency: Development \& Accomplishment; Ownership \& Possession; Scarcity \& Impatience; Loss \& Avoidance.

\section{The Main Ingredients of Gamification}

As we've discussed, gamification means using typical game dynamics and game-design elements in nongame contexts. "Through gamification, we can look through the lens of games to understand how to combine different game mechanics and techniques to form desired and joyful experiences for everyone." (Chou. 2015, p. 9-.10).

In general terms, game-design elements can be described as the recurring elements that we tend to find in every game that we have played in our lives, from "hide and seek" to table games and card games, to modern video games, to mobile game apps. Among the common elements of games, we find points, credits, scoring, rewards, levels, virtual goods, badges, achievements, leaderboard, challenges, goals, missions, resources, time, chance, strategy, aesthetics, theme, story and more (Boller. 2013).

Concerning the dynamics, Morschheuser, Maedche \& Walter (2017, February) propose to classify gamification into four categories: individualistic, competitive, cooperative, and cooperative-competitive.

Individualistic gamification engages the people involved without creating interdependence between goals of individuals (e.g., by the setting of independent 
goals).

Competitive gamification uses goal structures that invoke negative goal interdependence (e.g., the setting of competitive goals). According to- Chou (2015, p. 213-214), competition works when players aim to achieve mastery of the task, in gain-oriented scenarios and mindsets where players focus on becoming the winner. On the opposite, it does not work in learningfocused environments; in prevention-oriented situations and attitudes where players focus on not being the loser; when teams are too harmonious, and competition becomes awkward; when creativity is required; when the competition is regarded as skewed, and there is little chance to win.

Cooperative gamification uses goal structures that invoke positive goal interdependence (e.g., the setting of shared goals). Chou (2015, p. 213-214) argues that cooperative gamification brings individual strengths together and produces effective cooperation. In the long run, this formula will generally out-perform the individualistic paradigm of workplace motivation. Cooperative play can help preserve and improve a positive corporate culture, as well as support and encourage the development of talent and skills. At the same time, it increases competitive strength where it really matters - outside in the marketplace.

Cooperative-competitive gamification is based on groups, with positive goal interdependence within and negative goal interdependence between the groups (e.g., a team competition, where the team members have to cooperate among them to outperform their adversaries).

Using gamification successfully largely depends on a well-designed strategy built on a good understanding of the player, the mission and human motivation (Kumar and Herger. 2013).

\section{Gamification in Family Businesses}

Few have explored how gamification is used within family businesses. One notable exception is a Family Business Magazine article written by Holly Isdale (2015), CEO and founder of Wealtheven, entitled "How 'Gamification' Can Improve Family Education and Engagement." She studied families that used shared libraries to share news articles, and emailed questionnaires that generated discussions among family members about topics of interest. Family members' participation and success was acknowledged through prizes and pins that they proudly displayed in family retreats. Family members from the younger generation were particularly active and successful, what made them gain a higher recognition within the family.

This activity provided a low-cost, yet fun, educational tool to encourage discussion about the impact of broader market forces on the operating business; and challenged other family members to begin engaging more in the online community that had been developed. The family's Facebook posts changed from chatty updates on family news to links to relevant articles. Other families circulated quizzes about the family history and used badges to award family members who read and commented on articles. They found that these innovations not only increased family participation but also uncovered a desire for online learning. Other families have considered using gamification to explain their family history or to educate and engage younger members about the business.

Isdale also reports that families with very large shareholder groups are starting to work with gamification software developers to create robust online educational programming tools incorporating quests and games.

Along with families, universities are starting to embrace a gamification approach to family business education. In 2015, EDHEC Business School Family Business Centre, in collaboration with Deloitte, developed Pandora(https://www.edhec.edu/en/news/gamificationfamily-business-education) , a "serious game" in finance simulation for family businesses. Pandora uses the fictional Sanchez family business to simulate and explore financial decisions. As the webpage announcing the game reports, "the aim is to present the differences between key financial options, like private equity, bonds (convertible or not), asset sales, IPOs, debt, and so on, to members of business families who have little exposure to capital restructuring options and their possible consequences."

\section{Testimonials}

In the consulting world, Theresa Ramos, an FFI certified family business consultant at Premier Family Business Consulting, Inc. in the Philippines, has been advising family businesses to use games to develop their family constitution. She collected some testimonials from 
clients and shared them with the participants to the Family Business Asia Symposium, held at the Asian Institute of Management, in Manila, on April 24-27, 2019.

One of those testimonials commented that the games promoted teamwork and communication while keeping the mood light and fun as the family developed its constitution. The task of formulating a constitution can be quite draining, so the games were a great addition.

Another testimonial noted that instead of changing the relationship among family members, the games brought out the strengths of the different personalities involved. It was good to see how the contrast in skill was put to use.

A third testimonial said that communication was the key to completing the variety of games. It was a microcosm of how people should deal with one another in both family and work-related settings.

Another one says that the game "showed us that we need to communicate, be humble, and listen to each other. We realize we are different individuals just like the animals (referring to a game called "Animal Line") and we need to adjust to one another. The game helped loosen strained relations with the brothers and made family members able to open up with each other."

While not exhaustive, these cases offer a few examples of how gamification can be (and has been) used in the context of family businesses to explore the relationships among family members and induce or strengthen a shared sense of belonging to the family.

\section{What benefits can gamification bring to business families?}

The cases reported above offer good examples that gamification can have powerful effects for business families.

At the Family Business Asia Symposium 2019, Theresa Ramos reported Wenner's (2009) statement that free, imaginative play is crucial for normal social, emotional and cognitive development. It makes us better adjusted, smarter and less stressed. This thesis is repeatedly supported by research. A few examples can offer useful insights in this respect.

A team of neuroscientists at McGill University in Canada studied a sample of students to test "social stress" barriers to empathy between strangers. Among the findings: after only 15 minutes of playing Rock Band® together, strangers showed empathy toward one another (Martin et al. 2015).

Kolb's Experimental Learning Cycles suggest that plays are useful to generate insights thanks to the circular relationship between Active Experimentation, Concrete Experience, Reflective Observation and Abstract Conceptualization that is induced by the play (Kolb \& Kolb. 2005). This study echoes the thesis of John Dewey (1916), one of the most influential thinkers in educational theory in the 20th century, who noted that the effects of play on learning are maximized by the sum of Experiential Learning and Reflection.

We believe that games can bring social, emotional and cognitive benefits to family businesses, as the examples offered in the previous section show.

In Isdale's studies, the gamification involved both individualistic or competitive features -- and the overall payoff to the family exceeded the award the individual family member received for his/her learning or the contribution to the discussion. Most importantly, the games improved dialogue among family members; helped older members appreciate the younger members' contributions and perspectives; increased family participation and whetted everyone's desire for more online learning.

In the cases reported by Ramos, the gamification focused on cooperative features. The primary purpose of gamification was, in fact, to guide the participant family members to have fun and cooperate towards a common goal, leaving behind their personal frictions and misunderstandings and breaking down hierarchical barriers (age, family branch, position held in the company, etc.) Ramos and her colleagues used the Family Legacy Enterprise Game in advising business families. Her feedback from the family members emphasized these benefits:

It strengthens relationships and connections among participants, encourages involvement among family members, and adds value to a multi-disciplinary team.

It fosters engagement: it promotes participation and involvement, and learning together and applying those insights encourages commitment. 
It creates an atmosphere of good cheer: it lightens up the mood by becoming one of the players' fond family memories and becomes a welcome break from the "serious" workgroup.

It helps in the change process, teaching skills such as consensus building, effective communication, conflict management.

It facilitates insights for planning, team building and crafting the family constitution.

It adds value to a multi-disciplinary team of professionals helping the family business achieve the desired goal.

This feedback shows that the game sessions tend to build an environment where the participants can easily change their usual mindset, feel comfortable with expressing their opinions, and be actively involved in activities that enhance the so-called collective learning mechanisms (Senge, 1990).

Therefore, gamification in business families can encourage interaction, communication and collective learning, and help transform many activities - such as training, family meetings, and strategic planning sessions - into engaging and challenging games that entertain the participants. It provides an effective way to involve all family members in the decision making process, even those who don't fully understand governance, strategic planning, succession and other business topics.

This type of engagement is especially crucial for family members who are new to the business and how it works. By engaging a larger group of family members in the decision-making process, gamification can help the family to generate a common culture among family members and to strengthen their commitment to the firm.

\section{Useful Tools}

Literature on family business has developed a number of visual tools that can be used to this aim.

For instance, the three circles model (Davis, 1983; Tagiuri \& Davis, 1996, see below) can be used to invite family members to localize themselves in the "family business system" and start a discussion on how the position influences the perceptions, interests, and, more in general, the relationship with the family business.

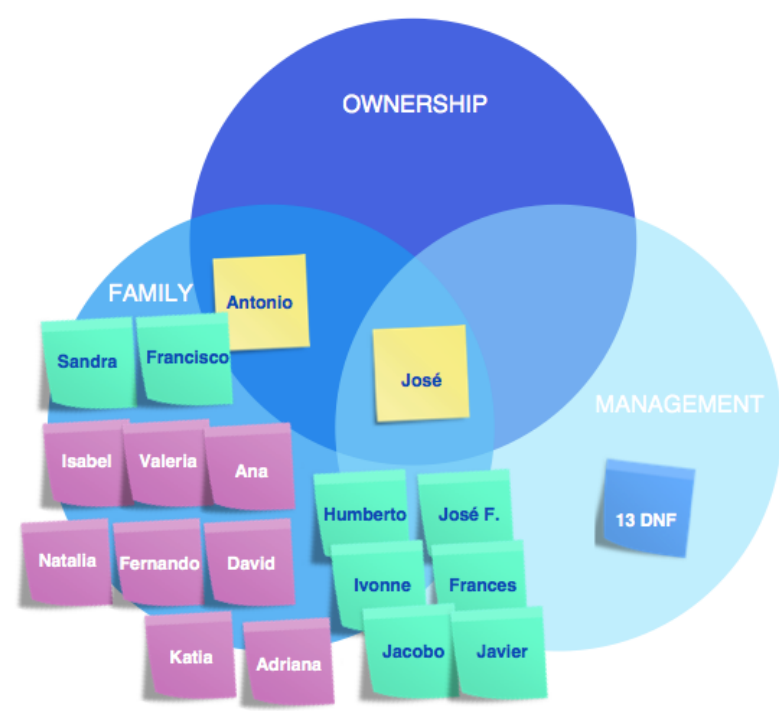

The "three-axis model", or "three-dimensional model" (Gersick, Davis, McCollom, Lansberg, 1997, below) can be used to explore how the perspective, interests, needs and expectations of individual family members change over time, depending on where they fit in the intersection between the family and ownership axes

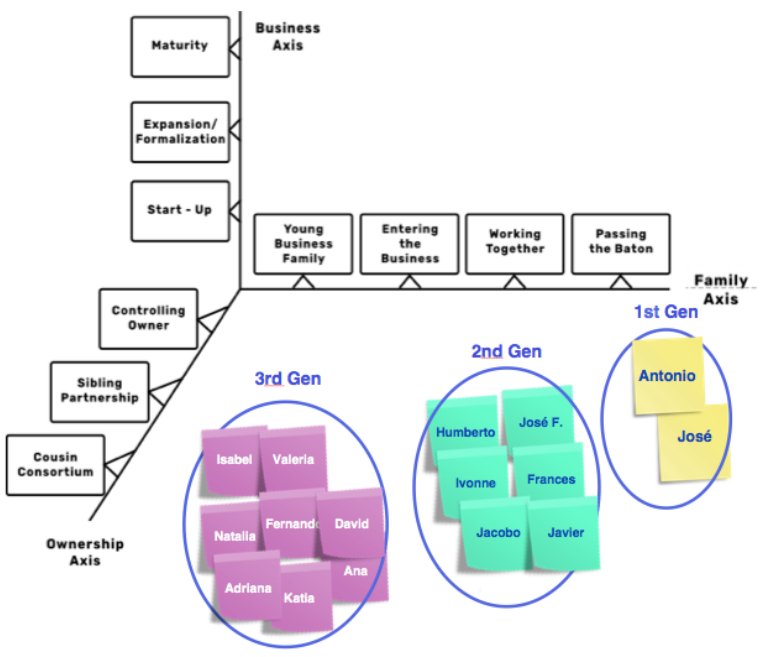

The Parallel Planning Process (Carlock \& Ward, 2001, below) can be used to guide a discussion on the dynamic relation between family and business strategic planning, and to support the design of a shared vision. 


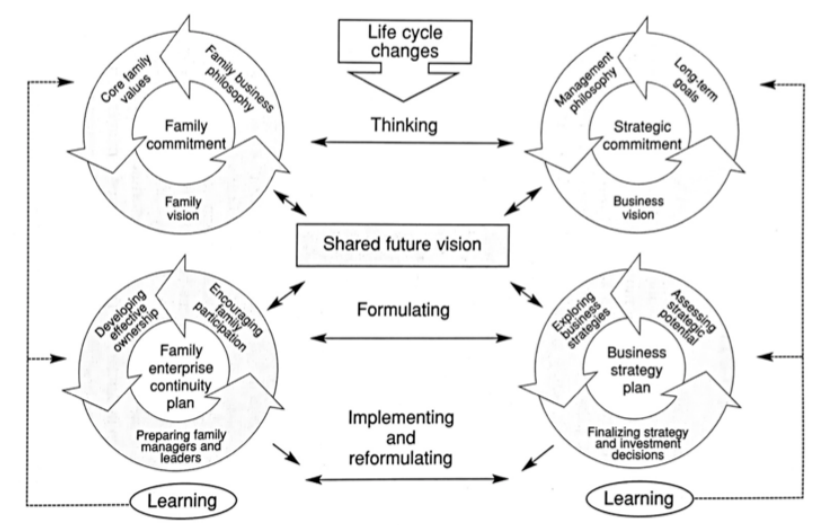

Carlock \& Ward, 2001

We have experienced that when family members are invited to "play" with these tools, using stick notes and informal dynamics to visualize the ongoing discussion, the level of engagement of family members grows, and their understanding of the characteristics of their family business is highly improved.

We feel that developing more gamified tools and training courses can be tremendously useful for business families. It can help them manage the relationship between the family and the business in a healthy and conscious way; acquire better familiarity with succession planning; make the experience of writing a family constitution an engaging and funny one; and turn business activities into a pleasant, and engaging experience for all the participants.

With a group of master students from my university, I have been working on the development of gamified consulting tools and training courses that can help family firms to manage the relationship between family and business in a healthy and conscious way. Our main aim is to make all those activities a pleasant and engaging experience for all the participants.

In a forthcoming article, we will present one of these tools and share how we have been using it with business families, and the feedback we received from participants.

\section{References}

Bo Kampmann, W. (2003). Playing and Gaming Reflections and Classifications. Game Studies. The International Journal of Computer Game Research. 3(1). $\quad$ http://gamestudies.org/0301/walther/ (http://gamestudies.org/0301/walther/)
Boller, Sharon LeBøllieg (2013)Game

Game Elements to Consider. http://www.theknowledge guru.com/learning-game-design-elements/.Accessedin August 2019.

Callois, R. (1958). Man, Play, and Games. New York: The Free Press. Cited in Bo Kampmann, W. 2003.

Carlock, R. S., Ward, J. L. (2001).Strategic planning for the family business: Parallel planning to unify the family and the business. New York: Palgrave Macmillan.

Chou, Y. (2015). "Actionable Gamification: Beyond Points, Badges, and Leaderboards". Octalys Media.

Dale, S. (2014). Gamification: Making work fun, or making fun of work?. Business Information Review.

Davis, P. (1983). Realizing the potential of the family business. Organizational Dynamics, 12(1): 47-57.

Deterding, S., Dixon, D., Khaled R., Nacke L. (2011). From Game Design to Gamefulness: Defining Gamification, $15^{\text {th }}$ International Academic MindTrek Conference: Envisioning Future Media Environments

Dewey, J. (1916). Democracy and Education: an introduction to the philosophy of education, New York: MacMillan. Quoted in Nicholson, S. (2012, March).

Gersick, K. E. Davis, J. A. McCollom, H. M., Lansberg, I. (1997). Generation to generation: Life cycles of the family business. Boston, MA: Harvard Business School Press.

Isdale, H. (2016). How 'Gamification' Can Improve Family Education and Engagement. Family Business Magazine. https://www.familybusinessmagazine.com/h ow-gamification-can-improve-family-education-andengagement- 0

Khaleel, F. L., Sahari, N., Wook, T. S. M. T., \& Ismail, A. (2016). Gamification elements for learning applications. International Journal on Advanced Science, Engineering and Information Technology, 6(6), 868-874.

Kolb, A. Y., \& Kolb, D. A. (2005). The Kolb learning style inventory - version 3.1: 2005 technical specifications. Boston: Hay Transforming Learning. www.haygroup.com/tl. 
Kumar, J. M. and Herger, M. (2013): Gamification Work: Designing Engaging Business Software. Aarhus, Denmark, The Interaction Design Foundation. ISBN: 978-87-92964-06-9.

Lumsden, J, Edwards EA, Lawrence NS, Coyle D, Munafò MR. (2016). Gamification of Cognitive Assessment and Cognitive Training: A Systematic Review of Applications and Efficacy. JMIR Serious Games.

Martin, L. J., Hathaway, G., Isbester, K., Mirali, S., Acland, E. L., Niederstrasser, N., Slepian, P.M., Trost, Z., Bartz, J.A., Sapolsky, R.M., Sternberg, W.F., Levitin, D.J., Mogil J.S. (2015). Reducing social stress elicits emotional contagion of pain in mouse and human strangers. Current Biology, 25(3), 326-332.

Morschheuser, B., Maedche, A., \& Walter, D. (2017, February). Designing cooperative gamification: conceptualization and prototypical implementation. In Proceedings of the 2017 ACM Conference on Computer Supported Cooperative Work and Social Computing (pp. 2410-2421). ACM.

Nicholson, S. (2012, March). Completing the experience: Debriefing in experiential educational games. In Proceedings of the 3rd international conference on society and information technologies (pp. 25-28). Winter Garden, Florida: International Institute of Informatics and Systemic.

Pinheiro, A., Patta, E.Z., Zaggia, J. (2015). Gamification to expand awareness about stress and its impacts within companies: gamification eustress and distress. CEUR Workshop Proceedings, pp. 22-31.

Rieber, L. P., Smith, L., \& Noah, D. (1998). The value of serious play. Educational Technology Saddle Brook NJ, 38(6), 29-37.

Senge, P. M. (1990). The fifth discipline: the art and practice of the learning organization. New York: Doubleday/Currency.

Tagiuri, R., Davis, J. (1996). Bivalent attributes of the family firm. Family Business Review, 9(2): 199-208.

Wenner, M. (2009). The serious need for play. Scientific American Mind, 20(1), 22-29.

Zichermann, G., Cunningham, C. (2011). Gamification by Design: Implementing Game Mechanics in Web and Mobile Apps. 1st ed. Sebastopol, CA, USA: O'Reilly Media, Inc.

Additional search terms: gaming, playing video games, family business strategies, family business conflict, family business planning 